\title{
Proof of concept of a method that assesses the spread of microbial infections with spatially explicit and non-spatially explicit data Ariel L Rivas*1,2, Kevin L Anderson ${ }^{1}$, Roberta Lyman ${ }^{1}$, Stephen D Smith ${ }^{3}$ and Steven J Schwager ${ }^{2}$
}

\author{
Address: ${ }^{1}$ Department of Population Health and Pathobiology, College of Veterinary Medicine, North Carolina State University, Raleigh, North \\ Carolina, USA, 2Department of Biological Statistics and Computational Biology, College of Agriculture and Life Sciences, Cornell University, \\ Ithaca, NY, USA and 'Institute for Resource Information Systems, College of Agriculture and Life Sciences, Cornell University, Ithaca, NY, USA \\ Email: Ariel L Rivas* - alr4@cornell.edu; Kevin L Anderson - Kevin_Anderson@ncsu.edu; Roberta Lyman - Roberta_Lyman@ncsu.edu; \\ Stephen D Smith - sds3@cornell.edu; Steven J Schwager - sjs5@cornell.edu \\ * Corresponding author
}

Published: 18 November 2008

International Journal of Health Geographics 2008, 7:58 doi:10.1 186/1476-072X-7-58

This article is available from: http://www.ij-healthgeographics.com/content/7/I/58

C 2008 Rivas et al; licensee BioMed Central Ltd.

This is an Open Access article distributed under the terms of the Creative Commons Attribution License (http://creativecommons.org/licenses/by/2.0), which permits unrestricted use, distribution, and reproduction in any medium, provided the original work is properly cited.

\begin{abstract}
Background: A method that assesses bacterial spatial dissemination was explored. It measures microbial genotypes (defined by electrophoretic patterns or EP), host, location (farm), interfarm Euclidean distance, and time. Its proof of concept (construct and internal validity) was evaluated using a dataset that included I I 3 Staphylococcus aureus EPs from I I 26 bovine milk isolates collected on 23 farms between 1988 and 2005.
\end{abstract}

Results: Construct validity was assessed by comparing results based on the interfarm Euclidean distance (a spatially explicit measure) and those produced by the (non-spatial) interfarm number of isolates reporting the same EP. The distance associated with EP spread correlated with the interfarm number of isolates/EP $(r=.59, P<0.02)$. Internal validity was estimated by comparing results obtained with different versions of the same indices. Concordance was observed between: (a) EP distance (estimated microbial dispersal over space) and EP speed (distance/year, $r=.72, P<$ 0.01 ), and (b) the interfarm number of isolates/EP (when measured on the basis of non-repeated cow testing) and the same measure as expressed by repeated testing of the same animals $(r=.87$, $P<0.01$ ). Three EPs (2.6\% of all EPs) appeared to be super-spreaders: they were found in $26.75 \%$ of all isolates. Various indices differentiated local from spatially disseminated infections and, within the local type, infections suspected to be farm-related were distinguished from cow-related ones.

Conclusion: Findings supported both construct and internal validity. Because 3 EPs explained 12 times more isolates than expected and at least twice as many isolates as other EPs did, false negative results associated with the remaining EPs (those erroneously identified as lacking spatial dispersal when, in fact, they disseminated spatially), if they occurred, seemed to have negligible effects. Spatial analysis of laboratory data may support disease surveillance systems by generating hypotheses on microbial dispersal ability. 


\section{Background}

Do all infections associated with the same microbial species possess similar spread ability? If not, methods that differentiate the ability of microbes to disseminate geotemporally could lead to improved prevention or control policy.

Historically, the study of microbial spread has not considered spatially explicit (latitude and longitude) data. With the emergence of geographical information systems (GIS), the spatial dissemination of bacterial strains (genotypes) can now be explored.

The assessment of infections on the basis of microbial spread speed has been justified before: the faster the spread, the greater its dispersion [1]. To measure microbial dispersal speed (distance/time), distance needs to be estimated. GIS approaches may be used to estimate whether microbial spread is related to interfarm distances.

Surveillance systems focusing on infections involve at least 3 factors: the microbe, the host, and the environment (space). To evaluate the spread of bacterial infections, all factors of the triad need to be investigated [2-8]. Recognition of disease patterns, trends, outliers, and/or unusual events is a major focus of surveillance systems $[9,10]$. To diagnose and treat an infected individual, it is necessary to collect information specific to individual subjects as well as information on the population subjects belong to. Dairy farms offer an opportunity to explore the dispersion patterns of microbes across bovine populations. When new patterns or outliers are observed, pattern discoveryoriented methods may support some hypotheses of disease types more strongly than other hypotheses. Before the generalizability of pattern discovery-oriented methods is determined, its "proof of concept" (construct and internal validity) needs to be explored [11].

Here, two dimensions of the proof of concept of a method that estimates microbial diffusion were investigated. To assess construct validity, data routinely collected in clinical laboratory settings were used to ask whether all infections associated with the same microbial species are similar in their ability to disseminate geo-temporally and, if not, whether different infection types could be suggested by the data. Second, it was asked whether alternative versions of the construct (with or without inclusion of additional variables that might control for potential sources of bias) could lead to different results (internal validity).

Operationally, the null research hypothesis was that no concordance among several versions of the evaluated method would be observed, while the alternative hypothesis was that at least two indices would yield similar results (a "triangulation" approach that assesses both construct and internal validity). Support of the null hypothesis would lead to abandoning further evaluations (e.g., not to engage in explorations of the generalizability of this method), while rejection of the null hypothesis would justify future studies with the purpose of exploring external (generalizability) and, in addition, statistical validity [11].

\section{Materials and methods \\ Collection of milk samples and identification of microbial subspecies}

Staphylococcus aureus ( $\mathrm{n}=1126$ isolates) was obtained from bovine milk samples (5-20 mL each) collected between 1988 and 2005 on 23 North Carolina dairy farms as the result of clinical work (a non-randomized dataset). $S$. aureus subspecies were characterized by pulsed field gel electrophoretic patterns (EP) [12]. Isolates were identified by: a) collection time, b) farm (latitude and longitude), c) animal, and d) EP descriptor.

\section{Unit of study}

The unit of study was multi-dimensional, which included: 1) the host, 2) the local site (farm), 3) microbial frequency, 4) interfarm (Euclidean) distance), and 5) annual microbial diffusion speed. For the purposes of this evaluation, the population of interest was the dataset under study. Because the dataset utilized was based on materials submitted to a mastitis diagnostic laboratory, no specific conclusions can be made with respect to the epidemiology of S. aureus mastitis in North Carolina.

\section{Spatial data and Geographical Information Systems- related procedures}

County-level data on dairy farms, dairy cows, and dairy farm size were obtained from the 2002 North Carolina Census of Agriculture [13]. Road data were collected from commercial archives (ESRI, Redlands, CA, USA). Farm spatial data were extracted from laboratory records.

An interfarm distance matrix $(\mathrm{km})$ was created using ArcView 3.3 and ArcGIS 9.2 as reported before [14]. It included 253 interfarm distances (not shown, available upon request). The distance each EP disseminated over space, if any, was assumed to be the Euclidean distance between farm pairs when only one new infected farm was added to the dataset over a year. For instance, in 1988, EP 38 was only found in farm 7 but, in 1991, it was found in farm 20 (Table 1), hence, EP 38 was assumed to disseminate $27.25 \mathrm{~km}$ between 1988 and 1991 (the distance between farms 7 and 20, not shown). When an EP was first reported in $\geq 2$ farms, later spreads were calculated as the average distance between farms. For instance, in 1988, EP 29 was reported in 3 farms $(1,2$, and 7$)$ and in 1990, it was isolated in farms 2 and 3; hence, its spread was 
Table I: EP temporal spread among farms infected between 1988 and 2005

\begin{tabular}{|c|c|c|c|c|c|c|c|c|c|c|c|c|c|c|c|c|c|c|c|}
\hline $\begin{array}{l}\text { EP ID\# } \\
(n=23)\end{array}$ & 88 & 89 & 90 & 91 & 92 & 93 & 94 & 95 & 96 & 97 & 98 & 99 & 00 & 01 & 02 & 03 & 04 & 05 & $\begin{array}{l}\text { Mean farms/ } \\
\text { year }^{\text {a }}\end{array}$ \\
\hline$\# 2$ & & & & & & & & & & & 2 & & & 2 & & & & & 0.50 \\
\hline$\# 5$ & & & & & & & & & & & 2 & 2 & 2 & 2 & & & & & 1.00 \\
\hline \# 7 & & & & & & & & & & & & & 10 & 1 & I & 3 & 3 & & 1.00 \\
\hline \# 10 & & & & I & & 1,37 & & 9 & & 4 & & 1,2 & 1,3 & 1 & I & I & & & 1.00 \\
\hline \# 13 & & & & & & & & & & & 2 & 2 & 2,36 & $1,2,6,7$ & I & 1,7 & 1 & & 1.86 \\
\hline \# 15 & & & & & & 7 & & 9 & & & 2 & 13,22 & $1,2,3$ & I & I & & & & 1.00 \\
\hline \# 16 & & & & & & & & & & & & 13 & 1 & 1 & 1,18 & 1 & & & 1.20 \\
\hline \# 17 & & & & & & 3,5 & & & & & & & I & & & I & $I$ & & 0.42 \\
\hline \# 26 & & & & & & & & & & & & 2 & & I & I & $i$ & & & 0.80 \\
\hline \# 27 & & & & & & & & & & & & & & 1 & I & I & 1 & & 1.00 \\
\hline \# 29 & $1,2,7$ & & 2,3 & 12 & & $1,2,5$ & 12 & & & 8 & 2 & $2,6,22$ & $1,23,622$ & $6,7,21$ & 1,2 & $1,7,17$ & $I, 4$ & 4 & 1.72 \\
\hline \# 30 & 2 & & & & & 2 & & & & & & 2 & 2 & 7 & I & I & 1,4 & 4 & 0.55 \\
\hline \# 31 & I & & & & & 2,3 & & & & & & & $2,3,6$ & 6 & 2 & & & & 0.53 \\
\hline \# 37 & & & & & & & & & & & & & & 2 & 2 & 2,3 & 1,2 & & 1.50 \\
\hline \# 38 & 7 & & & 20 & & 7 & & 7 & 7 & 8 & 2 & 2 & 2,3 & 2 & & 2,3 & 2,3 & 3 & 0.89 \\
\hline$\# 40$ & 2 & & 2 & & & & & & & & & & & & & & & 2 & 0.17 \\
\hline \# 46 & & & & & & & & & & & & & 3 & & & 2,3 & 2,6 & & 1.00 \\
\hline \# 53 & & & & & & & & & 14 & & & & & & & & & & 1.00 \\
\hline \# 58 & & & & & & & & & & & & & & 6 & 6 & 6 & 6 & & 1.00 \\
\hline \# 62 & & & & & & & & & & & & 22 & & & & 3 & 3,7 & & 0.67 \\
\hline \# 63 & & & & & & & & & 14 & & & & & & & 3 & & & 0.25 \\
\hline \# 64 & & & & & & & & & & & & & & & 3 & 3 & 3 & 3 & 1.00 \\
\hline \# 79 & & & & & & & & & & & & & & & 2 & 2,3 & 1,4 & & 1.67 \\
\hline
\end{tabular}

Columns indicate the year (two-digit number) each EP was reported, and the farm(s) where it was located. Numbers in italics refer to farm identifiers, not number of isolations.

a: Mean farms/year: number of farms where the EP was isolated/times (years when EP was isolated). For example, EP 2 was found in one farm (farm 2 ) in the first year it was observed, not found in the following 2 years, and found again in the last year it was observed ( 4 years in total, with I, 0,0 , and I findings, or a mean $=0.5$ )

taken to be the mean distance between farms 1 and 3, farms 2 and 3, and farms 7 and 3 (Tables 1,2). When an EP was later collected in $\geq 2$ farms (e.g., EP 10 in 1993), the distance was estimated as the averaged sum between the location of the farms reported earlier and the locations of farms reported later (e.g., for EP 10, the average of the sum between the distance between farm 1 and 3, and that between 1 and 7, Tables 1 and 2).

\section{Non-spatial and spatial indices of spatial (inter-herd) infection dispersal}

The dispersal of $S$. aureus was assessed with non-spatial and spatial measures. Non-spatial measures were those that lacked an explicit estimate of distance or speed (e.g., they were not expressed in kilometers). Non-spatial microbial diffusion was estimated as indicated by the number of isolates reporting the same EP. The isolates/EP relationship was expressed in percentages and calculated in two ways: (a) interfarm isolates/EP\% ([total count of isolates reporting the same EP on all farms/total count of isolates reporting any EP on all farms] $\times 100)$, and (b) intrafarm isolates/EP\% (total count of isolates reporting the same EP on a given farm/total count of isolates reporting any EP on the same farm] × 100).
In contrast, spatial measures considered distance $(\mathrm{km})$ and speed (km/year), or EPdist and EPspeed, respectively. Because spatial microbial dispersal may or may not be associated with (non-spatial) interfarm dispersal, an additional measure estimated the possible interaction between non-spatial and spatial factors: the EP geotemporal index (EPgeotemp, the product of interfarm isolates/EP and EPspeed). Therefore, 5 measures were used: 1) interfarm isolates $(E P, 2)$ intrafarm isolates/EP; 3) EPdist, 4) EPspeed; and 5) EPgeotemp. In this method, the interfarm (or intrafarm)isolates/EP measure acted as a de facto gold standard: it was assumed to be accurate.

The interfarm isolates/EP measure was calculated with 3 adjustments: 1) based on either repeated testing of the same cow or non-repeated testing of the same cow (where all isolates collected from the same cow and reporting the same EP were counted only once), or non-cow adjusted and cow-adjusted interfarm isolates/EP, respectively, 2) multiplying the interfarm isolates/EP (in either version) by the number of farms infected per EP (farm-adjusted interfarm isolates $(E P)$, and 3 ) multiplying the previous measure by the average number of farms infected/year (farm-, and timeadjusted interfarm isolates/EP). The purpose of multiplying the interfarm isolates/EP by the number of farms infected 
Table 2: Cumulative and annual EP spatial spread

\begin{tabular}{|c|c|c|c|c|}
\hline $\begin{array}{l}E P \text { ID } \\
(n=16)\end{array}$ & $\begin{array}{l}\text { Farms reporting EP } \\
\text { (farm ID) }\end{array}$ & $\begin{array}{c}\text { Cumulative distance } \\
\text { over } 18 \text { years (EPdist, } \\
\text { km) }\end{array}$ & $\begin{array}{c}\text { Years } \\
\text { (between first and last } \\
\text { isolation) }\end{array}$ & $\begin{array}{l}\text { Annual spread velocity between first } \\
\text { and last isolation (EPspeed, } \mathrm{km} / \text { year) } \\
\text { [C/D] }\end{array}$ \\
\hline $\mathbf{A}$ & B & C & D & $\mathbf{E}$ \\
\hline 15 & 7 to 9 , to 2 , to $13+22$, to $1+3$ & 965.46 & 9 & 107.27 \\
\hline 79 & 2 to 3, to $I+4$ & 208.01 & 2 & 104.01 \\
\hline 7 & 10 to 1 , to 3 & 389.58 & 4 & 97.40 \\
\hline 16 & 13 to 1, to 18 & 335.03 & 4 & 83.76 \\
\hline 37 & 2 to 3 , to $I$ & 175.58 & 3 & 58.53 \\
\hline 10 & I to $3+7$, to 9 , to 4 , to 2 & 643.87 & 12 & 53.65 \\
\hline 62 & 22 to 3 , to 7 & 203.23 & 5 & 40.65 \\
\hline 29 & $\begin{array}{l}1+2+7, \text { to } 3, \text { to } 12, \text { to } 5, \text { to } 8, \\
\text { to } 6+22, \text { to } 21, \text { to } 17, \text { to } 4\end{array}$ & 682.27 & 17 & 40.13 \\
\hline 46 & 3 to 2 , to 6 & 145.84 & 4 & 36.46 \\
\hline 30 & 2 to 7, to $I$, to 4 & 517.71 & 17 & 30.46 \\
\hline 13 & 2 to $3+6$, to 7 & 117.95 & 6 & 19.66 \\
\hline 38 & 7 to 20 , to 8 , to 2 , to 3 & 194.35 & 17 & 11.43 \\
\hline 63 & 14 to 3 & 69.50 & 7 & 9.93 \\
\hline 17 & $3+5$ to $l$ & 104.87 & II & 9.53 \\
\hline 26 & 2 to 1 & 37.36 & 4 & 9.34 \\
\hline 31 & I to $2+3$, to 6 & 113.63 & 14 & 8.11 \\
\hline Median & & 198.79 & 6.5 & 38.30 \\
\hline
\end{tabular}

A: Farm identifiers.

B: Estimated route of EP dissemination, based on farm location (as reported in Table I)

C: EP spatial spread $(\mathrm{km})$ over the entire length of the study period (18 years), or EPdist

$D$ : Time (years) between earliest and latest EP isolation

E: EP spread velocity ( $\mathrm{km} /$ year), or EPspeed

by each EP was to account for the possible bias due to a high number of isolates/EP concentrated in only one farm. The purpose of multiplying the farm-adjusted measure by the average number of farms infected/year was to control for disseminations concentrated at particular time periods.

Non-spatial indices of local (intra-herd) infection dispersal Local infections were assessed by simultaneously considering the percent of intrafarm isolates/EP and the percent of interfarm isolates/EP. When the interfarm measure was low or zero (minor or no EP spatial diffusion occurred) disease was classified as local, being labeled as "farm-related" if the intrafarm measure was high, or "cow-related" if the intrafarm measure was low.

\section{Descriptive quantitative analysis}

While not meant to generate inferences about generalizability or statistical significance, some statistical tests were applied to assess the construct and internal validity of the method evaluated. Linearity (the Ryan-Joiner test) and correlation analysis (Pearson test) were conducted with Minitab 15 (Minitab, State College, PA, USA).

\section{Results}

Background and descriptive information

The 23 investigated farms were located in counties that varied in farm size, farm density, dairy cow density, and road density (Fig. 1a-d). In those farms, 113 EPs were identified in 1126 isolates. Each EP was found, on average, 10 times (1126 isolates/113 EPs, or 9.96 isolates/EP).

Twenty-three EPs (23/113 or 20.35\% of all EPs) explained $85 \%$ of all isolates $(957 / 1126)$, or 4 times more cases than expected (85/20.35). Because, on average, each of these 23 EPs was found in 41.6 isolates $(957 / 23)$, they were regarded to be highly frequent (HF) EPs. The remaining 90 EPs (79.6\% of all EPs) were collected in $15 \%$ of all isolates (169/1126), explaining fewer cases (less than one fifth) than expected. The EPs found in only one isolate each were not analyzed. Only EPs found in $\geq 2$ isolates those with demonstrated ability to disseminate among animals- were analyzed further ( $\mathrm{n}=23 \mathrm{EPs})$.

Differences within the 23 HF EPs were also noticed in the percentage of isolates they explained: even after transformation, the (log) number of interfarm isolates/EP did not reveal linearity. Some EPs explained many more (less) cases than average (Fig. 1e).

By considering the number of EPs found per farm/year and the interfarm Euclidean distance, both the distance attributed to the $23 \mathrm{HF}$ EPs and their speed were estimated (Tables 1, 2, 3). Only 16 of the $23 \mathrm{HF}$ EPs appeared to show spatial spread (those found in $\geq 2$ farms). The remaining 7 HF EPs were isolated in only one farm each (Table 1). Hence, the data indicated two infection types: 

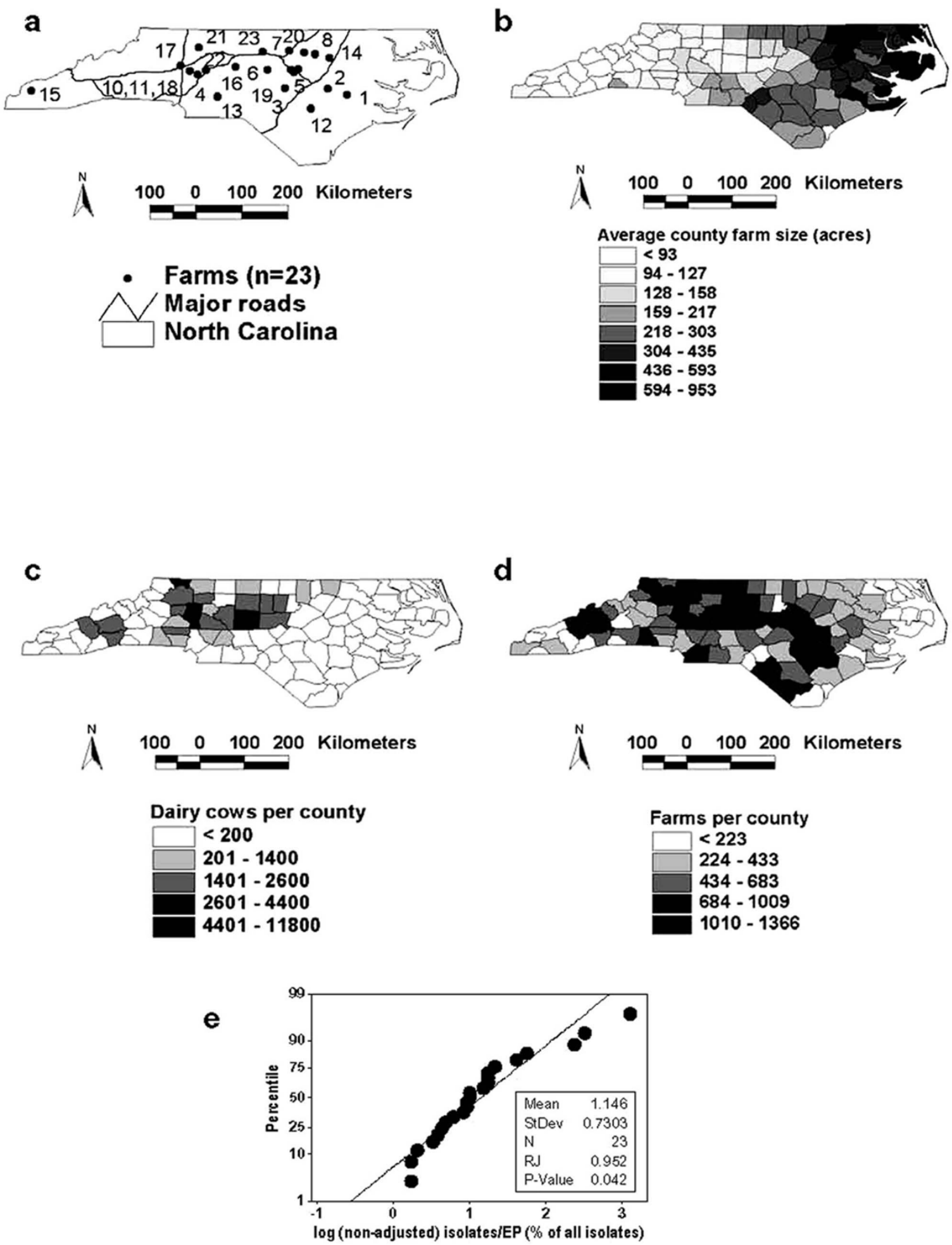

Figure I

Spatial context. Spatial location of: investigated farms and road network (a), farm size (b), dairy cows/county (c), and (farms/ county d). The Ryan-Joiner (RJ) test indicated that the (log) number of isolates/EP for the 24 microbial genotypes (EP) found in $\geq 2$ isolates (interfarm EP ratio) differed significantly $(P<0.05)$ from a normal distribution (diagonal line, e). 
Table 3: Cumulative and annual EP spread by the year 2000

\begin{tabular}{cccc}
\hline EP ID* & Cumulative EP spatial spread (EPdist, km) & Annual EP spread velocity (EPspeed, km/year) \\
\cline { 1 - 2 } \cline { 3 - 4 } 15 & 758.18 & 574.52 & 108.31 \\
10 & 456.58 & 63.83 \\
29 & 72.92 & 38.05 \\
13 & 221.54 & 36.46 \\
38 & 104.87 & 18.46 \\
17 & 112.69 & $\mathbf{1 4 . 9 8}$ \\
31 & 221.54 & 36.46 \\
\hline
\end{tabular}

*: Identifier of EPs isolated, at least, in $\geq 2$ farms in $\geq 3$ different years between 1988 and 2000. Both EPdist and EPspeed indicated that EP/5 displayed values at least 3 times greater than the median.

a

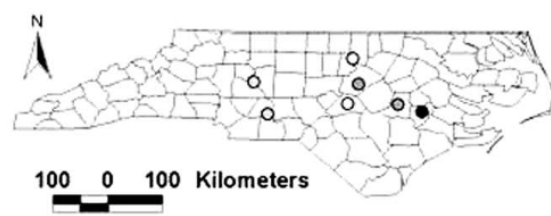

EP \# 15

○ 1993

- 1995

○ 1998

- 1999

- 2000

- 2001

- 2002

North Carolina counties b

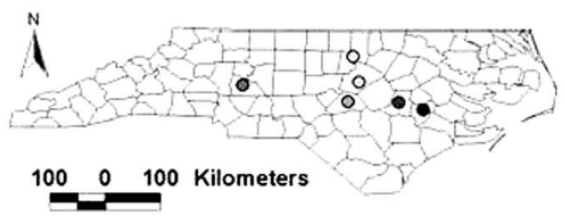

EP \# 10

O $1991-1992$

- $1993-1994$

- 1995 - 1996

- 1997

- $1998-1999$

- $2000-2001$

- 2002-2003

North Carolina counties

C
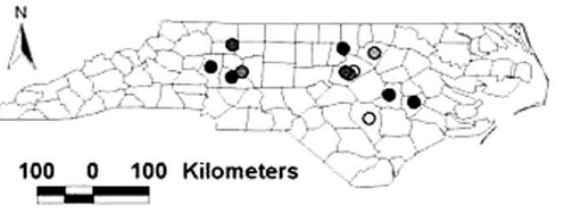

EP \# 29

- 1988- 1990

- 1990- 1994

- 1994-1999

- 1999-2000

- 2000-2001

- 2001-2003

- 2003-2005

North Carolina counties

d

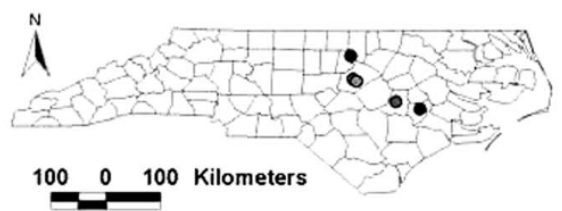

EP \# 13

○ 1998

○ 1999

- 2000

- 2001

- 2002

North Carolina counties e

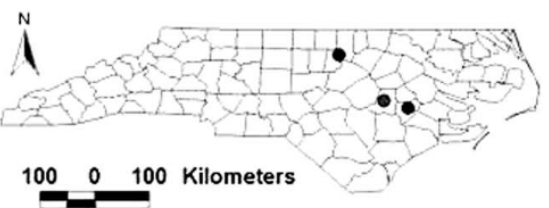

EP \# 30

O 1988

- 1993 $1993-200$

$1993-2000$
- $2000-2002$

North Carolina counties f

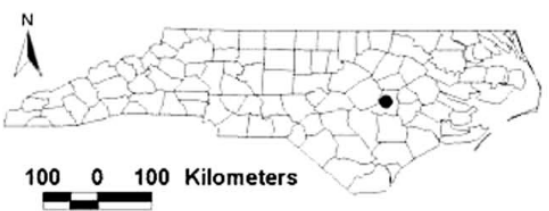

EP \# 5

○ 1998

- 1999

- 2000

- 2001

North Carolina counties

\section{Figure 2}

Spatial diffusion profiles of S. aureus subspecies (EPs). High (large) spatial and high (faster) temporal diffusion ( $a$, and $b$ ), high spatial and low (slower) temporal diffusion (c), low (small) spatial and low temporal diffusion (d), low spatial and low temporal diffusion (e), and local (not spatial), although frequent, diffusion $(f)$. Maps display only the most recent observation on a given farm (previous observations on the same location may have occurred). 
with and without spatial diffusion (across- and withinherd spread, respectively).

Across-herd infections revealed 4 patterns, characterized by: a) high speed and high spatial diffusion, b) low speed and low spatial diffusion, c) high speed and low spatial diffusion, and d) low speed and high spatial diffusion (Fig. 2). The data differentiated 2 sub-types within the local (within-herd) diffusion type: farm-related and animal-related infections.

\section{Differentiation of spatially diffused (microbial-driven or across-herd) infections}

By ordering the data according to year and location (farm) each EP was reported, the EP diffusion distance (EPdist) was estimated. Among the 16 HF EPs that spread over space, the EPdist varied, within 18 years, between 37.36 and 965.46 $\mathrm{km}$ (Table 2, column C). When the distance between infected farms was divided by the number of years each EP was detected (the time elapsed between its earliest and latest isolation), the speed EPs spread at varied between 8.11 and $107.27 \mathrm{~km} /$ year (EPspeed, Table 2, column E).

In the spatially-disseminated infection type, neither the farm nor the cow explained disease: infection was mainly explained by highly frequent (HF) and highly spatially disseminated (HSD) EPs (i.e., those appearing to disseminate spatially above the median, Table 2). Farm 7 was an example of a site where this infection type appeared to occur: between 1988 and 1993, it was infected by HF and HSD EPs (e.g., EPs 10, 15, 29, Table 1).

Because not all EPs were observed in all years, EPdist and EPspeed were not always associated. For instance, EP 30 seemed to disseminate above the median distance but below the median speed. Vice versa, EP 37 (which showed below average EPdist) displayed above average EPspeed (Table 2, columns $\mathrm{C}, \mathrm{E}$ ).

Speed differences were noticed among EPs. For instance, by the year 2000, EP 15 spread at a rate 3 times faster than the median speed of the remaining EPs (Table 3 ). If measures against EP 15 had been adopted in that year (and achieved success), they could have reduced the total (cumulative) EPdist of EP 15 by $21.5 \%$ (or $207.28 \mathrm{~km}$, Tables 2 and 3 ).

Almost half of the 957 isolates where the 23 HF EPs were found, were produced by repeated testing of the same cows (Table 4, columns A-C). To prevent bias, these $23 \mathrm{HF}$ EPs were also assessed on the basis of single-cow testing data $(\mathrm{n}=485$ isolates, Table 4 , columns $\mathrm{D}, \mathrm{E})$.

The multiplication of the interfarm isolates/EP by the number of farms where each EP was found produced a measure that reflected spread beyond the boundaries of a given farm (although it did not assess distance): the (farm-adjusted) number of interfarm isolates reporting the same EP (Table 4, columns F-H). That measure was further multiplied by the mean number of sites infected per year by a given EP (a non-spatial measure that addressed the effect of time, Table 4, columns I-K). By multiplying that value by EP distance (a spatially explicit measure), the EP geo-temporal index (EPgeotemp) was obtained (Table 4, columns $\mathrm{M}, \mathrm{N}$ ).

The two measures of the interfarm isolates/EP index (the repeated-cow testing and the single-cow testing versions) correlated $(\mathrm{r}=.87, P<0.01$, Fig. $3 \mathrm{a})$. To determine the spatial diffusion associated with each $\mathrm{EP}$, the values of the 16 EPs that revealed spatial diffusion were log-transformed. Several indices identified 3 EPs (10,15 and 29) as disseminating geo-temporally above the $75^{\text {th }}$ percentile (Figs. 3b-e). This means that $75 \%$ of all EPs explained fewer isolates than EPs 10,15 and 29. These 3 EPs (2.6\% of all EPs) explained $26.75 \%$ of the non-adjusted (repeated cow-testing based) interfarm isolates (10 times more cases than expected, Table 4, column C), or 32.98\% of all the adjusted (single-cow testing based) interfarm isolates (12 times more cases than expected, Table 4, column E). Hence, EPs 10, 15, and 29 were estimated to be super-spreaders: they showed both high frequency and high geo-spatial dissemination, revealing values at least twice higher than other spatially disseminated EPs.

The spatially explicit EPdist (the construct under analysis) was significantly associated with the non-spatial measure of microbial dispersal (the variable regarded to be the gold standard): the (single cow-, farm-, and timeadjusted) interfarm isolates/EP correlated with EPdist $(\mathrm{r}=$ $.59, P<0.02$, Fig. 3f). Two indications of internal validity were observed: 1) EPspeed correlated with EPdist $(r=.72$, $P<0.01$, Fig. 3g); and 2) the EPgeotemp index calculated on the basis of repeated testing of the same cow correlated with the index obtained in single-cow testing $(\mathrm{r}=.98, P<$ 0.01, Fig. 3h).

\section{Differentiation of locally diffused (not spatially disseminated or within-herd) infections}

The intrafarm isolates/EP supported a "farm-related" infection hypothesis when it was high (when $>50 \%$ of the isolates found in a farm reported the same EP) and, in addition, the EPgeotemp index was low or zero (when poor or no spatial diffusion was observed). "Farm-related" infections were suspected in farm 14 (Fig. 4), where EPs 53 was found in $67 \%$ of the isolates (Table 5), but zero EPdist was observed and, therefore, no EPspeed (no acrossherd dispersion) occurred.

In contrast, "cow-related" infections were suggested when the EPgeotemp index was average or low, and the percentage of intrafarm isolates/EP was low (many EPs were found 
Table 4: Bacterial non-spatial, spatial, and composite (non-spatial and spatial) diffusion

\begin{tabular}{|c|c|c|c|c|c|c|c|c|c|c|c|c|c|}
\hline $\begin{array}{c}\text { EP ID } \\
(n=23)\end{array}$ & $\begin{array}{l}\text { Iso-lates } \\
(n=957)\end{array}$ & $\begin{array}{l}\text { Iso-lates/EP } \\
(\%, \mathrm{~B} / 957)\end{array}$ & $\begin{array}{l}\text { (cow-adj.) } \\
\text { Iso-lates } \\
(n=485)\end{array}$ & $\begin{array}{c}\text { (cow-adj.) } \\
\text { Iso-lates/EP } \\
(\%, D / 485)\end{array}$ & $\begin{array}{l}\text { No. of } \\
\text { farms }\end{array}$ & $\begin{array}{c}\text { (non-cow- } \\
\text { adj.) } \\
\text { Isolates/EP/ } \\
\text { farm } \\
(\mathrm{C} \times \mathrm{F})\end{array}$ & $\begin{array}{l}\text { (cow-adj.) } \\
\text { Isolates/EP/ } \\
\text { farm }(E \times F)\end{array}$ & $\begin{array}{c}\text { Mean } \\
\text { farms/year/ } \\
{[\mathrm{MFY}]}\end{array}$ & $\begin{array}{c}\text { (non-cow } \\
\text { adj.) } \\
\text { Isolates/EP/ } \\
\text { farm/MFY } \\
(\mathrm{G} \times \mathrm{I})\end{array}$ & $\begin{array}{c}\text { (cow-adj.) } \\
\text { Isolates/EP/ } \\
\text { farm/MFY } \\
(\mathrm{H} \times \mathrm{I})\end{array}$ & $E P$ dist $(\mathrm{km})$ & $\begin{array}{c}\text { (non-cow } \\
\text { adj.) EP } \\
\text { geo-temp } \\
(J \times L)\end{array}$ & $\begin{array}{c}\text { (cow adj.) } \\
\text { EP geo- } \\
\text { temp } \\
(\mathrm{K} \times \mathrm{L})\end{array}$ \\
\hline$A$ & B & C & $\mathrm{D}$ & $E$ & $\mathrm{~F}$ & $\mathrm{G}$ & $\mathrm{H}$ & 1 & $J$ & $\mathrm{~K}$ & L & M & $\mathrm{N}$ \\
\hline \multicolumn{11}{|c|}{ Nonspatial (frequency) data } & Spatial & \multicolumn{2}{|c|}{ Nonspatial \& spatial } \\
\hline 29 & 117 & 12.2 & 59 & 12.2 & 12 & 146.4 & 146.4 & 1.72 & 252.34 & 251.808 & 682.27 & 172163 & 171801 \\
\hline 10 & 103 & 10.8 & 70 & 14.4 & 6 & 64.8 & 86.4 & 1.00 & 64.58 & 86.400 & 643.87 & 41579 & 55630 \\
\hline 15 & 36 & 3.8 & 31 & 6.4 & 7 & 26.6 & 44.8 & 1.00 & 26.33 & 44.800 & 965.46 & 25423 & 43253 \\
\hline 79 & 33 & 3.4 & 11 & 2.3 & 4 & 13.6 & 9.2 & 1.67 & 23.03 & 15.364 & 208.01 & 4791 & 3196 \\
\hline 13 & 55 & 5.7 & 28 & 5.8 & 5 & 28.5 & 29.0 & 1.86 & 53.45 & 53.940 & 117.95 & 6304 & 6362 \\
\hline 38 & 214 & 22.4 & 62 & 12.8 & 5 & $1 / 2.0$ & 64.0 & 0.89 & 99.51 & 56.960 & 194.35 & 19340 & 11070 \\
\hline 16 & 26 & 2.7 & 14 & 2.9 & 3 & 8.1 & 8.7 & 1.20 & 9.78 & 10.440 & 335.03 & 3277 & 3498 \\
\hline 46 & 21 & 2.2 & 12 & 2.5 & 3 & 6.6 & 7.5 & 1.00 & 6.58 & 7.500 & | 45.84 & 960 & 1094 \\
\hline 30 & 24 & 2.5 & 16 & 3.3 & 4 & 10.0 & 13.2 & 0.55 & 5.52 & 7.260 & $5|7.7|$ & 2856 & 3759 \\
\hline 37 & 13 & 1.4 & 7 & 1.4 & 3 & 4.2 & 4.2 & 1.50 & 6.11 & 6.300 & 175.58 & 1073 & 1106 \\
\hline 7 & 25 & 2.6 & 6 & 1.2 & 3 & 7.8 & 3.6 & 1.00 & 7.84 & 3.600 & 389.58 & 3053 & 1402 \\
\hline 62 & 12 & 1.3 & 6 & 1.2 & 3 & 3.9 & 3.6 & 0.67 & 2.52 & 2.412 & 203.23 & 512 & 490 \\
\hline 17 & 48 & 5.0 & 14 & 2.9 & 3 & 15.0 & 8.7 & 0.42 & 6.32 & 3.654 & 104.87 & 663 & 383 \\
\hline 31 & 18 & 1.9 & 9 & 1.9 & 4 & 7.6 & 7.6 & 0.53 & 3.99 & 4.028 & 113.63 & 453 & 458 \\
\hline 26 & 26 & 2.7 & 17 & 3.5 & 2 & 5.4 & 7.0 & 0.8 & 4.35 & 5.600 & 37.36 & 162 & 209 \\
\hline 63 & 12 & 1.3 & 11 & 2.3 & 2 & 2.6 & 4.6 & 0.25 & 0.63 & 1.150 & 69.50 & 44 & 80 \\
\hline 53 & 33 & 3.4 & 33 & 6.8 & 1 & 3.4 & 6.8 & 1.00 & 3.45 & 6.800 & 0.00 & 0 & 0 \\
\hline 2 & 33 & 3.4 & 31 & 6.4 & 1 & 3.4 & 6.4 & 0.5 & 1.72 & 3.200 & 0.00 & 0 & 0 \\
\hline 5 & 16 & 1.7 & 14 & 2.9 & 1 & 1.7 & 2.9 & 1.00 & 1.67 & 2.900 & 0.00 & 0 & 0 \\
\hline 40 & 19 & 2.0 & 11 & 2.3 & 1 & 2.0 & 2.3 & 0.17 & 0.34 & 0.391 & 0.00 & 0 & 0 \\
\hline 64 & 31 & 3.2 & 10 & 2.1 & 1 & 3.2 & 2.1 & 1.00 & 3.24 & 2.100 & 0.00 & 0 & 0 \\
\hline 27 & 25 & 2.6 & 9 & 1.9 & 1 & 2.6 & 1.9 & 1.00 & 2.61 & 1.900 & 0.00 & 0 & 0 \\
\hline 58 & 17 & 1.8 & 4 & 0.8 & 1 & 1.8 & 0.8 & 1.00 & 1.78 & 0.800 & 0.00 & 0 & 0 \\
\hline
\end{tabular}

A: EP identifier (of EPs found in $\geq 2$ isolates, accounting for $\geq 1 \%$ of all isolates)

B: Isolates/EP (repeated-cow testing, total number of isolates $[n=957]$ )

C: Percentage of isolates/EP (repeated-cow testing, percentage of all isolates ["C"= "B"/957 × 100])

$D$ : Isolates/EP (single-cow testing, total number of isolates, $[n=485]$ )

E: Percentage of isolates/EP (single-cow testing, percentage of all isolates ["E"= "D"/485 × 100])

F: Number of farms where a given EP was found

G: Number of isolates/EP (repeated-cow testing, multiplied by number of farms ["G"= "C" × "F"])

$\mathrm{H}$ : Number of isolates/EP (single-cow testing, multiplied by number of farms [" $\mathrm{H} "=$ "E" $\times$ "F"])

I: Mean number of farms/year in the year(s) the EP was found (or MFY, same as reported in Table I)

$\mathrm{J}$ : Number of isolates/EP (repeated-cow testing, times farm/EP, and farms/year ["J"= "G" × "I"])

$\mathrm{K}:$ Number of isolates/EP (single-cow testing), times farm/EP, and farms/year ["K"= "H" × "I"])

L: EPdist ( $\mathrm{km}$, as reported in Table 2, column C)

M: EPgeo-temp index (repeated-cow testing based ["M"="]" × "L"])

$\mathrm{N}$ : EPgeo-temp index (single-cow testing based ["N"="K" × "L"]) 

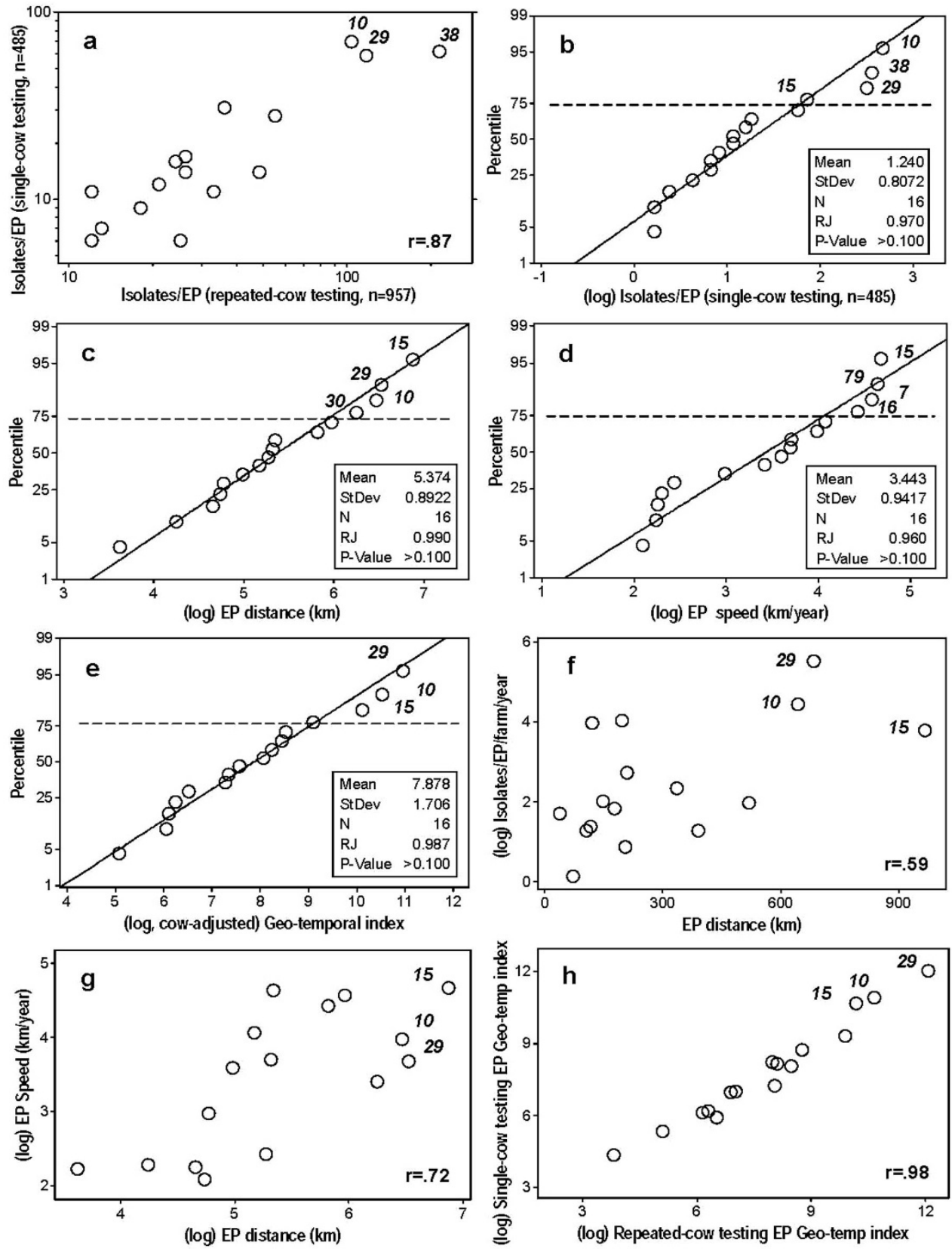

\section{Figure 3}

Non-spatial and composite (non-spatial and spatial) microbial diffusion. The number of EP-specific interfarm isolates correlated significantly between repeated and single testing of the same animals $(r=.87, P<0.01$, as indicated in Table 4 , columns $B$ and $D, a$ ). Four indices that estimate bacterial diffusion are described: the (single-cow testing based) number of isolates/ EP (as indicated in Table 4, column E, b), the distance assumed each EP disseminated over time (EP distance, as indicated in Table 2, column C, c); the EP diffusion velocity (EPspeed, as indicated in Table 2, column E, $d$ ); and the product of (fully adjusted) interfarm isolates/EP and EP speed (the fully adjusted geo-temporal or EPGeotemp index, as indicated in Table 4, column N, e). Diagonal lines indicate the expected distribution under the hypothesis of linearity. The null hypothesis of lack of normality was rejected (Ryan-Joiner [RJ] test $>0.05$ ). Significant correlations were observed (i) between the isolates/EP index (adjusted for single-cow testing, number of farms, and time) and EPdist $(r=.59, P<0.02$, as indicated in Table 4, columns J and $\mathrm{L}, \mathrm{f}$ ), (ii) between EPdist and EPspeed ( $r=.72, P<0.0 \mathrm{I}$, as indicated in Table 2, columns $C$ and $E$, $g$ ), and (iii) between both versions of the EPGeotemp index (non-repeated vs. repeated testing of the same cow, $r=.98, P=0.0 \mathrm{I}$, as indicated in Table 4, columns $\mathrm{M}$ and $\mathrm{N}, h$ ). Numbers in italics identify EPs above the $75^{\text {th }}$ percentile or displaying the highest values. 
within a farm, so no individual EP represented $>50 \%$ of all isolates reported in the farm). "Cow-related" disease was suspected in farms 2, 8, and 6 (a set representing 25\% of all farms with $\geq 6$ isolates, Table 5 and Fig. 4). For instance, the EP most frequently isolated in farm 2 (EP 2) had a low percentage of intrafarm isolates/EP (12.5\%) and no spatial diffusion (zero EPgeotemp, Tables 4 and 5).

Although affecting different cows, some farms revealed $\geq$ 2 infection types. For instance, a double profile appeared to occur in farm 13, where the two most frequently isolated EPs (16 and 42) showed high and low EPspeed, respectively (Table 5 ). A triple profile was shown in farm 2, where (a) an EP lacking spatial spread (EP 5) was observed in four consecutive years (suggesting a "farmproblem" type, Table 1), (b) the EP most frequently isolated (EP 2) revealed a low percentage of intrafarm isolates/ $E P$ and no spatial spread, indicating a "cow-related" problem (Tables 4 and 5), and (c) EPs with high EPgeotemp indices $(10,15,29$, and 79$)$ were also observed (Table 4$)$.

\section{Discussion}

This study explored whether the use of multi-dimensional indices (which included spatially explicit data) could differentiate infections in terms of their ability to disseminate across subjects, space, and time. Because test validation requires the assessment of construct, internal, external, and statistical dimensions, this report focused on the "proof of concept" (the first two dimensions). Unless construct and internal validity are defensible, the evaluation of the remaining dimensions may not be justified [11]. Because only one dataset was assessed, no conclusions could be made about (a) the generalizability of the findings, and (b) the statistical model appropriate for this method.

While transmission and contagiousness are separate concepts (e.g., one microbe may be highly contagious within a farm but not isolated across farms, while another microbe may be found in many places and times but only infecting a marginal proportion of animals), the scenario under analysis supported the hypothesis that transmission and contagiousness tend to be associated. Regardless of the (unknown) mechanism of dissemination or transmission, 3 EPs explained a higher percentage of isolates, revealing higher values of spatial-temporal dissemination than the remaining EPs.

While the data supported the overall hypothesis that infections can be differentiated on the basis of their ability to disseminate, the major issue of interest was whether the basic measure estimated by the method under analysis

Table 5: Local (non-spatial) analysis: intrafarm and interfarm isolates/EP (\%) and EP speed

\begin{tabular}{|c|c|c|c|c|c|c|c|c|c|}
\hline Farm ID & $\begin{array}{l}\text { Farm iso- } \\
\text { lates }\end{array}$ & $\begin{array}{c}\text { Farm } \\
\text { isolates in } \\
\text { cows tested } \\
\text { once }\end{array}$ & $\begin{array}{c}\text { EPs per } \\
\text { farm }\end{array}$ & $\begin{array}{l}\text { MF iso- } \\
\text { lates/EP }\end{array}$ & $\begin{array}{c}\text { MF isolates/ } \\
\text { EP/cows } \\
\text { tested once }\end{array}$ & $\begin{array}{c}\text { Intra-farm } \\
\text { isolates/EP } \\
(\%)\end{array}$ & $\begin{array}{c}\text { Adjusted } \\
\text { intrafarm } \\
\text { isolates/EP } \\
(\%)\end{array}$ & MF EP (ID) & $\begin{array}{c}\text { Interfarm } \\
\text { isolates/ } \\
\text { EP\% }\end{array}$ \\
\hline A & B & C & D & $\mathbf{E}$ & $\mathbf{F}$ & G & H & I & J \\
\hline 14 & 49 & 49 & 5 & 33 & 33 & 67.34 & 67.3 & 53 & zero \\
\hline 9 & 6 & 5 & 3 & 3 & 3 & 50.0 & 50.0 & 10 & high \\
\hline 22 & 6 & 6 & 3 & 3 & 3 & 50.0 & 50.0 & 29 & high \\
\hline 5 & 17 & 15 & 6 & 7 & 6 & 41.18 & 35.3 & 60 & low \\
\hline 13 & 6 & 6 & 4 & 2 & 2 and 2 & 33.33 & 33.3 & 16 and 42 & $\begin{array}{c}\text { Average, } \\
\text { low }\end{array}$ \\
\hline 7 & 29 & 28 & 16 & 6 & 6 & 20.69 & 20.6 & 29 & high \\
\hline 3 & 302 & 126 & 25 & 181 & 59 & 59.9 & 19.5 & 38 & high \\
\hline 1 & 362 & 194 & 38 & 90 & 58 & 24.8 & 16.02 & 10 & high \\
\hline 4 & 58 & 19 & 8 & 26 & 9 & 44.82 & 15.5 & 79 & high \\
\hline 2 & 240 & 167 & 34 & 33 & 33 & 13.7 & 12.5 & 2 & zero \\
\hline 8 & 9 & 9 & 9 & 1 & 1 & II.II & II.I & $\begin{array}{l}29,38,56 \\
57,67,69 \\
71,72,76\end{array}$ & high, low \\
\hline 6 & 60 & 21 & 15 & 17 and 17 & 4 and 4 & 28.33 & 6.7 & 29 and 58 & high, zero \\
\hline
\end{tabular}

A: Farm identifier

B: Total number of isolates collected in the farm

C: Total numbers of isolates collected from different cows of the farm

$D$ : Total number of EPs found in the farm

E: Number of isolates of the EP most frequently (MF) found in the farm

$F$ : Number of isolates of the MF EP found in cows tested once in the farm

G: Percent of all farm isolates reporting the MF EP ("G"= "E"/"B")

$\mathrm{H}$ : Percent of all farm isolates reporting the MF EP, based on non-repeated cow testing ("H"="F"/"B")

I: Identifier of the MF EP isolated in the farm

J: Low, average, high: below the $50^{\text {th }}$ (low) or $75^{\text {th }}$ (average) percentile, or above the $75^{\text {th }}$ percentile, respectively, as reported in Table 4 and Fig. 3 (be). 


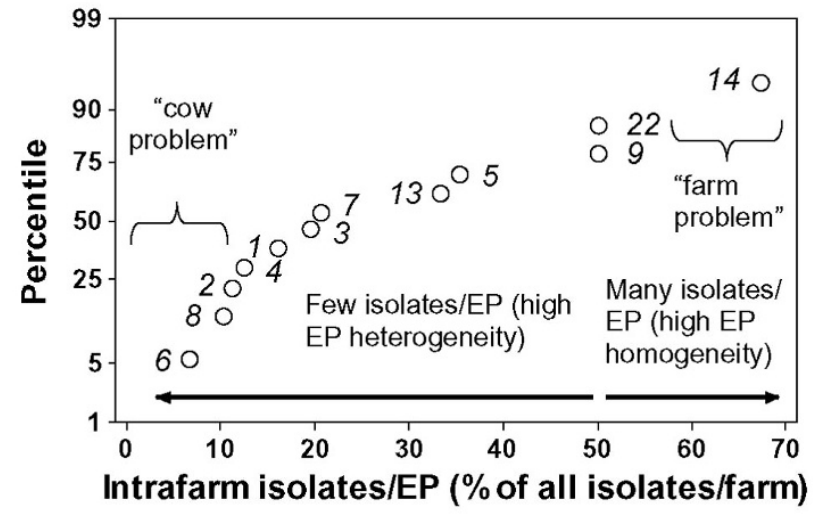

\begin{abstract}
Figure 4
Local (non-spatially disseminated) infection hypotheses. The 12 farms that contributed with $\geq 6$ isolates were assessed in terms of intrafarm isolates/EP (percentage of isolates of a given farm reporting the same EP). Numbers identify farms (the same as reported in Table 5). Because the farm displayed in the upper right quadrant showed a high intrafarm isolates/EP index (67\% of all isolates collected in farm 14 pertained to the same EP) but no spatial diffusion (zero EPspeed, see Tables 4 and 5), a "problem farm" hypothesis was supported. In contrast, no EP predominated in the 3 farms identified in the lower left quadrant $(6,8,2)$ : EPs collected in those farms explained $<13 \%$ of all isolates and displayed no spatial diffusion, profile that supported an "animalproblem" hypothesis.
\end{abstract}

(which includes the use of interfarm Euclidean distance as estimator of microbial diffusion) possessed construct validity. Unknown and/or unmeasured factors, taking place over 18 years, could have influenced the observed findings, generating false negative and/or positive results (underestimating and/or overestimating the actual microbial diffusion). Hence, two questions were asked to address construct and internal validity issues: 1) did all EPs explain a similar percentage of isolates?, and 2) did the non-spatial and spatial diffusion measures correlate?

The first question was answered negatively. The second question was answered positively. The high correlation observed between the repeated- and the non-repeated isolates/EP data provided an additional evidence of internal validity $(r=.87$, Fig. 3a).

Several indices identified 3 EPs $(10,15$, and 29, Figs. 3af) as highly spatially diffused (HSD) and highly frequent (HF). These EPs explained at least twice as many cases as explained by other EPs. That finding was not unexpected: Woolhouse's "20:80" rule has been reported in many infectious diseases. That rule indicates that a minor proportion of "cases" (in this scenario, a minor percent of EPs) explains most of the disease diffusion (epidemic) process [15-17].
These findings were relevant to assess the validity of this method: they suggested that what mattered was not whether the (interfarm Euclidean distance-based) spatial measure under study exactly reflected the true distances and/or speeds associated with the dissemination of $S$. aureus-mediated intramammary infections. Instead, the question of interest was whether the created (spatial) construct could adequately identify the EPs that contributed most to disease spread. Due to the "20:80" rule, the errors that may actually matter are those that involve the EPs displaying ultra-high frequency and/or spatial dissemination. No discrepancies were observed in relation to EPs 10, 15, and 29. If some EPs were erroneously assumed to either lack spatial dissemination when in fact they spread spatially, or dispersed more than they actually did but disseminated below the 75 percentile, those errors would have negligible impact: the EPs that disseminated spatially below the 75 percentile only explained a minor percentage of isolates (they appeared to possess a marginal contagiousness).

The same EPs contributing most to infection dispersal were detected by both the non-spatial and spatial measures. Because the spatially explicit diffusion measure (EPdist) correlated with the non-spatially explicit diffusion measure (interfarm isolates/EP), errors due to actual spatial dissemination routes and/or speeds different from estimated were assumed to be inconsequential.

The "triangulation" approach followed in this method may expand the information available to decision-makers, facilitating their ability to detect inconsistencies. For example, EP 38 was identified as highly disseminated by the (single cow-based) interfarm isolates/EP measure (Fig. $3 b)$, but it was not so identified when spatially explicit measures were considered (Figs. $3 \mathrm{c}-\mathrm{e}$ ).

Future versions of this method could include additional variables, not assessed here or only partially described (Fig. 1a-d). For instance, disease spread could be expressed by the number of new farms infected per new year. Other measures to consider include: a) non-Euclidean distances ("along roads" interfarm distance), as described elsewhere (18); b) proximity to major highways; c) contact tracing (contacts between farms and/or between farms and markets); d) regional traffic (e.g., the influence of human and animal population density [19]); e) farm management practices; and f) immunity $[12,18,20]$. For example, the data shown in Figs. 1a-d could, in future assessments, investigate the association between highly frequent EPs and factors that may facilitate or prevent microbial dispersal (e.g., high vs. low road/ farm/animal density, as reported elsewhere [21]).

This method addressed two needs so indicated by the disease surveillance literature: 1 ) the relative lack of multivar- 
iate indicators, and 2) the production of spatial disease maps. Multivariate indicators are expected to describe disease spread more validly than univariate indicators $[22,23]$. Spatial disease maps promote the generation of location-specific decisions [24].

The data supported two hypotheses of local (within-herd) infection. A local disease profile suggests that some (unknown) interaction may occur between the bacterial agent and local actors such that, EPs that in other farms seem to be mildly pathogenic, may induce infections. Local infection types were found within one third of all farms contributing with $8805 ; 6$ isolates. When the EP spatial spread was poor and the percent of intrafarm isolates/EP was above average (when high EP homogeneity was observed within a farm, and no spatial diffusion was noticed), a "problem farm" was suspected [25]. When an EP was found in only one farm (e.g., if EPgeotemp was zero), the hypothesis of a "problem farm" became even stronger, as observed in farm 14 (Tables 1 and 4).

The second local infection type ("cow-related") was suggested when the percent of intrafarm isolates/EP was low (many EPs were observed within a farm) and the infecting EPs showed poor or no spatial diffusion. In this type, disease was suspected to be neither microbial-driven nor farm-related but cow-related [26]. This profile was displayed by farms 2, 6, and 8 , which showed high intrafarm EP heterogeneity (many EPs were observed within each farm) and poor spatial spread.

Data on repeated isolations of the same EP from the same cow may be valuable in some instances. When the same $\mathrm{EP}$ is repeatedly isolated from the same cow and it neither reveals a high spatial diffusion nor it predominates in the farm (there is no evidence of either a microbial-driven or a farm-related problem), the host may be suspected to be the problem (e.g., an immune-related problem may be hypothesized).

The presence of mixed infection types in some farms indicated that some herds were not homogeneous. This finding documented that epidemiologic models based on the theory of homogenous population mixing may be invalid [27].

Differentiation of infection types, based on their diffusion ability, may lead to type-specific inquiries. When a farmrelated infection is suspected (noticed in farm 14), inquiries focusing on management, water quality, or local climate may be warranted. When "cow-related" infection is suspected, investigations on the immune response, nutrition, and/or genetics may be indicated [28].

The indices here described could support epidemiological inquiries (Additional file 1). They could also be applied to detect bacterial epidemics of "slow" diffusion that, otherwise, could remain undetected. False negative results (e.g., no discrimination among infection types and sub-types) and/or delayed detection of changes in disease patterns may occur when the individual scale (a single animal) is considered. However, when the population is evaluated over time and space, changes in infection diffusion patterns may become noticeable at earlier times.

Given the high percentage of isolates explained by highly spatially disseminated (HSD) and highly frequent (HF) EPs, even a minor success rate in noticing such infection type could substantially reduce the overall number of cases. If, in this scenario, only one of the 3 EPs showing the largest dispersal had been identified early (and successfully treated), between 6 and 14 percentage points of disease occurrence could have been prevented. Provided that other criteria (e.g., data quality, frequent testing) are also met, if assessed prospectively, the use of geo-temporal data could result in early detection of disease pattern changes, facilitating less costly or more beneficial decisions $[9,10,22-24,29,30]$.

\section{Conclusion}

Hypotheses on infection categories, classified on the basis of geo-temporal dissemination, were generated by the method under analysis. Because the interfarm Euclidian distance correlated with the isolates/EP measure and the estimated EP distance correlated with the estimated EP speed, the method seemed to possess both construct and internal validity. Further studies are recommended to explore external and statistical validity issues.

While the subjects investigated in this study were domestic animals, the methodology here described and evaluated is potentially applicable in human medicine. Two reasons support the previous statement: 1) the variables analyzed are routinely collected or potentially collected by diagnostic laboratories of human infectious diseases; and 2) while the bacterial strains analyzed in this study do not seem to infect humans, the bacterial species here assessed is a major pathogen affecting humans. While the construct and internal validities of the model evaluated could have been explored with a simulated geo-temporal dataset, we chose to assess an actual scenario, which happened to contain data from domestic animals. That selection, however, may have an advantage over either simulated studies or studies conducted with human populations: domestic animal populations are usually less prone to outside interactions (animal populations, such as herds, are relatively closed and, therefore, more apt to investigate within- and between-population factors than human populations). Hence, what here is described as a farm or herd can be considered to represent a relatively closed human environment. 


\section{Competing interests}

The authors declare that they have no competing interests. ALR and SJS are coauthors of a patent in process that measures interfarm distances as here described.

\section{Authors' contributions}

ALR conceived the study, performed the analysis, and drafted the manuscript. KLA and RL carried out the microbiological studies and provided farm geo-referenced data. SJS created the method used to calculate interfarm distances. SDS produced the geo-referenced dataset and calculated the interfarm distances. All authors read and approved the final manuscript.

\section{Additional material}

\section{Additional file 1}

Examples of data-driven questions, further inquiries, and possible decisions.

\section{Click here for file}

[http://www.biomedcentral.com/content/supplementary/1476072X-7-58-S1.doc]

\section{References}

I. Trevelyan B, Smallman-Raynor M, Cliff AD: The spatial dynamics of poliomyelitis in the United States: from epidemic emergence to vaccine-induced retreat, 1910-1971. Ann Assoc Amer Geogr 2005, 95:269-293.

2. Stärk KDC, Regula G, Hernandez J, Knopf L, Fuchs K, Morris RS, Davies $P$ : Concepts for risk-based surveillance in the field of veterinary medicine and veterinary public health: Review of current approaches. BMC Health Serv Res 2006, 6: I-8.

3. Koopman J: Modeling infection transmission. Annu Rev Public Health 2004, 25:303-326.

4. Carvalho EM, Bastos LS, Araujo MI: Worms and allergy. Parasite Immunol 2006, 28:525-534.

5. Hon KLE, Nelson EAS: Gender disparity in paediatric hospital admissions. Ann Acad Med Singapore 2006, 35:882-888.

6. Viboud C, Bjornstad ON, Smith DL, Simonsen L, Miller MA, Grenfell BT: Synchrony, waves, and spatial hierarchies in the spread of influenza. Science 2006, 31 2:447-45I.

7. Peschel A, Jack RW, Otto M, Collins LV, Staubitz P, Nicholson G, Kalbacher H, Nieuwenhuizen WF, Jung G, Tarkowski A, van Kessel KPM, van Strijp JAG: Staphylococcus aureus resistance to human defensins and evasion of neutrophil killing via the novel virulence factor MprF is based on modification of membrane lipids with L-lysine. J Exp Med 2001, 193:1067-1076.

8. Diep BA, Carleton HA, Chang RF, Sensabaugh GF, Perdreau-Remington F: Roles of 34 virulence genes in the evolution of hospitaland community-associated strains of methicillin-resistant Staphylococcus aureus. J Infect Dis 2006, I 93:|495-I503.

9. Hand DJ, Bolton RJ: Pattern discovery and detection: a unified statistical methodology. I Appl Stat 2004, 3 I:885-924.

10. Woodall WH: The use of control charts in health-care and public-health surveillance. J Qual Technol 2006, 38:89-104.

II. Cook TD, Campbell DT: Quasi-experimentation Boston, Houghton Mifflin; 1979.

12. Anderson KL, Lyman RL, Bodeis-Jones SM, White DG: Genetic diversity and antimicrobial susceptibility profiles among mastitis-causing Staphylococcus aureus isolated from bovine milk samples. Am J Vet Res 2006, 67: I I85- II91.

13. North Carolina Department of Agriculture and Consumer Statistics, Agricultural Division, County Statistics [http:// www.agcensus.usda.gov/Publications/2002/County Profiles/ North Carolina/index.asp]
14. Chowell G, Rivas AL, Smith SD, Hyman KM: Identification of case clusters and counties with high infective connectivity in the 2001 epidemic foot-and-mouth disease in Uruguay. Am J Vet Res 2006, 67:102-1I3.

15. Woolhouse MEJ, Dye C, Etard JF, Smith T, Charlwood JD, Garnett GP, Hagan P, Hii JLK, Ndhlovu PD, Quinnell RJ, Watts CH, Chandiwana SK, Anderson RM: Heterogeneities in the transmission of infectious agents: implications for the design of control programs. Proc Natl Acad Sci USA 1997, 94:338-342.

16. Koopman JS, Simon CP, Riolo CP: When to control endemic infections by focusing on high-risk groups. Epidemiology 2005, 16:621-627.

17. Fedler KA, Biedenbach DJ, Jones RN: Assessment of pathogen frequency and resistance patterns among pediatric patient isolates: report from the 2004 SENTRY Antimicrobial Surveillance Program on 3 continents. Diagn Microbiol Infect Dis 2006, 56:427-436.

18. Rivas AL, Smith S, Sullivan PJ, Gardner B, Hoogesteijn AL, CastilloChávez $C$ : Identification of geographical factors associated with early epidemic spread of Foot-and-Mouth Disease. Am J Vet Res 2003, 64:1519-1527.

19. Rivas AL, Kunsberg B, Chowell G, Smith SD, Hyman JM, Schwager SJ: Human-mediated Foot-and-Mouth Disease epidemic dispersal: disease and vector clusters. J Vet Med B 2006, 53: I- I0.

20. Rivas AL, Schwager SJ, González RN, Quimby FW, Anderson KL: Multifactorial relationships between intramammary invasion by Staphylococcus aureus and bovine leukocyte markers. Can J Vet Res 2007, 7 I: |35-|44.

21. Rivas AL, Schwager SJ, Smith S, Magri A: Early and cost-effective identification of high risk/priority control areas in foot-and mouth disease epidemics. J Vet Med B 2004, 5 I:263-27I.

22. Rogerson PA, Yamada I: Monitoring change in spatial patterns of disease: comparing univariate and multivariate cumulative sum approaches. Stat Med 2004, 23:2195-2214.

23. Kaltenthaler E, Maheswaran R, Beverley C: Population-based health indexes: a systematic review. Health Policy 2004, 68:245-255

24. Rodeiro CLV, Lawson AB: Monitoring changes in spatio-temporal maps of disease. Biom J 2006, 48:463-480.

25. Swai ES, French NP, Karimuribo ED, Fitzpatrick JL, Bryant MJ, Brown $\mathrm{PE}$, Ogden NH: Spatial and management factors associated with exposure of smallholder dairy cattle in Tanzania to tickborne pathogens. Int J Parasitol 2005, 35: I085-1096.

26. Foster TJ: Immune evasion by Staphylococci. Nature Microbiol 2005, 3:948-958.

27. Colizza V, Barthlemy M, Barrat A, Vespignani A: Epidemic modeling in complex realities. C $R$ Biologies 2007, 330:364-374

28. Rivas AL, Tadevosyan R, Quimby FW, Lein DH: Blood and milk cellular immune responses of mastitic non-periparturient cows inoculated with Staphylococcus aureus. Can J Vet Res 2002, 66: $|25-| 3 \mid$.

29. Knowles RL, Smith Alan, Lynn Richard, Rahi Jugnoo S: Using multiple sources to improve and measure case ascertainment in surveillance studies: $\mathbf{2 0}$ years of the British Paediatric Surveillance Unit. J Public Health (Oxf) 2006, 28: I57-I65.

30. Potter ME: Use of epidemiologic data to measure the impact of food safety control programs. Food Control 2006, 1 7:825-837.

Publish with Bio Med Central and every scientist can read your work free of charge

"BioMed Central will be the most significant development for disseminating the results of biomedical research in our lifetime. "

Sir Paul Nurse, Cancer Research UK

Your research papers will be:

- available free of charge to the entire biomedical community

- peer reviewed and published immediately upon acceptance

- cited in PubMed and archived on PubMed Central

- yours - you keep the copyright
BioMedcentral 